NBER WORKING PAPER SERIES

\title{
INSURANCE, SELF-PROTECTION, AND THE ECONOMICS OF TERRORISM
}

\author{
Darius Lakdawalla \\ George Zanjani \\ Working Paper 9215 \\ http://www.nber.org/papers/w9215 \\ NATIONAL BUREAU OF ECONOMIC RESEARCH \\ 1050 Massachusetts Avenue \\ Cambridge, MA 02138 \\ September 2002
}

We are grateful to Steven Garber, Dana Goldman, Steven Haider, Jack Hirshleifer, Arie Kapteyn, Jim Poterba, Robert Reville, and numerous seminar participants at RAND for helpful discussion and comments. We thank Priya Gandhi for research assistance. Lakdawalla is grateful for the support of RAND's Institute for Civil Justice. The views expressed in this paper are those of the authors and do not necessarily reflect the positions of the Federal Reserve Bank of New York, the Federal Reserve System, the National Bureau or RAND.

(C) 2002 by Darius Lakdawalla and George Zanjani. All rights reserved. Short sections of text, not to exceed two paragraphs, may be quoted without explicit permission provided that full credit, including (C) notice, is given to the source. 
Insurance, Self-Protection, and the Economics of Terrorism

Darius Lakdawalla and George Zanjani

NBER Working Paper No. 9215

September 2002

JEL No. H0

\begin{abstract}
$\underline{\text { ABSTRACT }}$
This paper investigates the rationale for government intervention in the market for terrorism insurance, focusing on the externalities associated with self-protection. Self-protection by one target encourages terrorists to substitute towards less fortified targets. Investments in self-protection thus have negative external effects in the presence of rational terrorists. Government subsidies for terror insurance can discourage self-protection and limit the inefficiencies associated with these and other types of negative externalities. They may also serve as a complement to a policy of publicly provided protection.
\end{abstract}

Darius Lakdawalla

RAND

1700 Main Street

Santa Monica, CA 90407

and NBER

darius@rand.org

George Zanjani

Capital Markets Function

Federal Reserve Bank of New York

33 Liberty Street

New York, NY 10045

george.zanjani@ny.frb.gov 


\section{Introduction}

Soaring prices for terrorism coverage after September 11, 2001 led to calls for government intervention in the insurance market (McCool, 2001). Such appeals are not uncommon after significant shocks to the insurance industry. Examples include the crisis in the liability insurance market of the late 1980's (sparked by asbestos-related lawsuits) and the crisis in the catastrophe reinsurance market of the early 1990's (sparked by Hurricane Andrew), both of which were accompanied by failed campaigns for federal intervention. Yet, the current push for federal involvement appears to have reasonable prospects for success.

Such success would have precedent. Government provision of terrorism coverage is common in developed countries that face a serious threat. Both the Israeli and British governments participate in terrorism coverage (McCool, 2001), although they shun direct involvement in other apparently similar catastrophe markets. Will the U.S. follow suit? If so, what distinguishes the terror insurance market from other markets with similar risk profiles? ${ }^{1}$

This paper argues that much of both the normative case and the practical impetus for intervention lie not in the nature of terror risk - which, like that of natural disasters, is both hard to predict and hard to diversify - but in the externalities associated with self-protection. Market failure in this case arises because of fully informed, rational behavior. Potential targets of terrorism have incentives to protect themselves against attack, but rational terrorists will substitute away from fortified targets and toward vulnerable ones. Therefore, self-protection by one agent encourages attacks on others, but this consequence is not considered by the agent that invests in protection. Government subsidies of terror coverage can dissuade agents from substituting self-protection for insurance when self-protection has these negative external effects. Hence, although economists usually compare terrorism risk with natural catastrophe risk when discussing public intervention, we argue that better analogies are drawn with deposit insurance and war-risk life insurance - where the real issues hinge on self-protection. ${ }^{2}$

The effects of self-protection (Ehrlich and Becker, 1972) extend beyond the calculus of individual optimization problems in two respects. First, an agent's decision to self-protect may affect the price of insurance faced by other agents. Examples include anti-theft devices in automobiles, which may change overall insurance prices by affecting the behavior of thieves, ${ }^{3}$ and automobile safety, which may change prices by affecting the behavior of protected drivers or the damages associated with accidents

\footnotetext{
${ }^{1} \mathrm{~A}$ general analysis of and review of the literature on catastrophe insurance markets is provided by Froot (1997).

${ }^{2}$ Hirshleifer (1953) provides one of the first analyses of insurance and self-protection decisions in the context of war risk.

${ }^{3}$ In one of the few empirical analyses of externalities in private self-protection, Ayres and Levitt (1998) show that Lojack vehicle recovery systems generate positive externalities since the Lojack system is unobserved.
} 
(Peltzman, 1975). Second, self-protection decisions may generate externalities that affect society as a whole. For example, trigger-happy bank depositors spark liquidity crises and thereby affect the operating performance of the economy (Diamond and Dybvig, 1983).

When faced with such externalities, government policy can influence self-protection through the use of taxes and subsidies. The obvious approach is to apply taxes, subsidies, or regulations directly to the self-protection behaviors that generate externalities, in the tradition of Pigovian welfare economics (Pigou, 1932). However, if self-protection is difficult to define, monitor, or measure, the government can also influence self-protection choices by instead taxing or subsidizing the purchase of insurance. Since insurance and self-protection are substitutes from the perspective of the individual, a policy aimed at encouraging the purchase of insurance simultaneously discourages self-protection. Thus, government subsidization of insurance can be interpreted, ironically, as a policy geared toward encouraging moral hazard.

Still another approach is the provision of public protection. Distorting an unsubsidized (and thus efficient) market for insurance through subsidies is initially costless, on the margin. Therefore, even in the presence of public protection, some amount of insurance subsidization remains optimal. Moreover, in many important cases, subsidies and public protection are actually complements. It is not surprising that the two are often observed in tandem, as is the case with deposit insurance and banking regulation.

The rest of this paper is organized as follows. Section 2 presents a simple model of terrorist behavior, and develops its implications for the probability of terrorist attack, and its relationship to private self-protection. Given these attack probabilities, Section 3.1 explores individual decision making by targets of terror, while Section 3.2 investigates the effects of government policies regarding insurance subsidies and public protection.

\section{Terrorist Behavior and the Probability of Attack}

If we were considering insurance and self-protection against, say, natural disasters, we could take as given the probability of loss as a function of self-protection. The probability of terrorist attack though is the outcome of interaction between terrorists and their targets. In this section, we present a simple model of terrorist behavior and use it to derive some important properties for the probability of terrorist attacks. ${ }^{4}$ In particular, if terrorists respond to self-protection by targets, this can create externalities in protection. ${ }^{5}$

Consider a "syndicate" of terrorists, criminals, or soldiers with resources $R$ intent on attacking a set of $N$ targets. From the syndicate's perspective, the probability of

\footnotetext{
${ }^{4} \mathrm{An}$ analysis of terrorist behavior is also presented in Major (2002).

${ }^{5}$ An analysis of criminal deterrence and the associated externalities is offered in Eck (1993).
} 
succeeding against any given target depends upon what they spend attacking it, and what the target spends on self-protection. ${ }^{6}$ The source of the externalities lies in the responses of terrorists to private self-protection.

When terrorists inflict the loss $L$ on target $j$, they receive the benefit $B(L) .{ }^{7}$ The probability of inflicting this loss is a function $\rho\left(s_{j}, r_{j}\right)$, where $s_{j}$ is the self-protection expenditure of target $j$, and $r_{j}$ is the level of resources spent by terrorists on attacking target $j$, so that $\rho_{s}<0$ and $\rho_{r}>0$ with the concavity conditions $\rho_{s s}>0$ and $\rho_{r r}<0$. Expenditures on self-protection make terrorist investments less productive, so that $\rho_{s r}<0$. Terrorists have available resources $R$, which may be affected by the selfprotection of targets, according to $R\left(s_{1}, \ldots, s_{N}\right)$. For example, by lowering the returns to terrorist activity, self-protection could discourage its funding.

After the self-protection levels have been set, terrorists allocate their resources across $N$ targets according to:

$$
\begin{array}{r}
\max _{r_{i}} \sum_{i=1}^{N} \rho\left(s_{i}, r_{i}\right) B(L) \\
\text { s.t. } \sum_{i=1}^{N} r_{i} \leq R\left(s_{1}, \ldots, s_{N}\right)
\end{array}
$$

The first order conditions of this problem equate the marginal productivity of terrorist resources across all targets:

$$
\rho_{r}\left(s_{i}, r_{i}\right)=\rho_{r}\left(s_{j}, r_{j}\right)
$$

If we perform comparative statics in a symmetric equilibrium with identical targets, we obtain:

$$
\begin{aligned}
\frac{\partial r_{i}}{\partial s_{i}} & =\frac{(N-1)\left(-\rho_{r s}\right)+\rho_{r r} \frac{\partial R}{\partial s_{i}}}{N \rho_{r r}} \\
\frac{\partial r_{j}}{\partial s_{i}} & =\frac{\rho_{r s}+\rho_{r r} \frac{\partial R}{\partial s_{i}}}{N \rho_{r r}}
\end{aligned}
$$

Increases in self-protection result in a substitution effect and a wealth effect on terrorism. Protection by one target causes terrorists to substitute resources toward

\footnotetext{
${ }^{6}$ The self-protection expenditures of other targets has no effect on this probability. We abstract from technological externalities, such as a surveillance camera that provides protection to a whole neighborhood.

${ }^{7} \mathrm{We}$ assume here that the value of inflicting a loss is independent of the target's level of selfprotection. This may not always be the case: terrorists may value the destruction of well defended targets simply as a demonstration of their capabilities. In this case, there could be a "race to the bottom" in self-protection, where every target would attempt to undercut the others in protective investments.
} 
other targets; this substitution effect is embodied by $\rho_{\text {rs }}<0$. In other words, each target's probability of attack falls with its own self-protection, but rises with the self-protection investments of others. On the other hand, wealth effects arise if selfprotection affects terrorist resources.

Absent wealth effects (e.g., if $R$ is fixed), the appendix shows that $\frac{\partial r_{i}}{\partial s_{i}}<0$ and $\frac{\partial r_{j}}{\partial s_{i}}>0$. In this case, the substitution effects dominate. Terrorists substitute away from the fortified target and toward other targets, yielding negative externalities in protection.

The case of no wealth effects seems a relevant one for global terrorist groups, for several reasons. First, there may be no substitute for terrorism, in the sense that extremist groups without political wings may view it as their only option. If so, internal funding levels may not respond to self-protection or other changes in the returns to terrorism. Furthermore, many factors - such as the power of states that sponsor terrorism, a history of religious or ethnic conflict, or the perceived wrongdoing of the targeted society or group - influence terrorists' external funding levels. These factors are probably of more direct importance to terrorists' funding levels than selfprotection. In the context of these other factors, the influence of self-protection may not be large.

Although we abstract from wealth effects for most of our discussion, one should bear in mind their possibilities. If protection makes terrorists poorer $\left(R_{s}<0\right)$, they will spend less on all targets. This reinforces the substitution effect associated with $s_{i}$ for target $i$, but could offset the effect for the other targets $j \neq i$. Terrorists will always spend less attacking the target that defended itself, but the net change in resources spent on other targets is ambiguous. On the other hand, protection could make terrorists richer. For example, if outside sponsors seek to maximize terror, increases in self-protection after an attack might be interpreted as signs of insecurity and taken as an indicator of success, leading to more funding. In this case, the wealth effect would counteract the substitution effect for target $i$, but reinforce it for the other targets.

Wealth effects also raise an interesting issue with respect to alternative specifications of the terrorist problem. We have structured the static problem with selfprotection levels taken as fixed inputs to the terrorist problem, implicitly assuming that targets commit to self-protection levels in advance of the terrorist attacks. Without precommitment, however, terrorists would not take self-protection levels as given. They would consider the impact of their strategies on self-protection choices and, hence, their current or future funding. This complication is beyond the scope of this paper.

An illustration of the potential importance of wealth effects is provided by the case of unobserved protection. So far, we have assumed that self-protection is observable to terrorists. This seems a reasonable assumption, since terrorists can observe security guards, surveillance cameras, fences, military installations, the vigilance of airport or other screeners, or the accessibility of a location. Moreover, terrorists 
have incentives not to attack targets about which they know little. However, in certain specific cases of crime or terrorism, protection may be unobserved, and this can have important consequences. For example, as Ayres and Levitt (1998) have shown, Lojack - a tracking device on automobiles designed to recover vehicles in the event of theft - is unobservable. Criminals cannot tell which cars have Lojack installed and appear to be discouraged from stealing as a result. This is a case where unobservable protection has positive externalities. Self-protection yields benefits for all, even the unprotected.

To see this formally, suppose terrorists or criminals know only the mean level of self-protection, $\bar{s}$, but not the self-protection of a particular target. In this case, the syndicate solves the problem:

$$
\begin{aligned}
& \max _{r_{i}} E\left[\sum_{i} \rho\left(s_{i}, r_{i}\right) B(L) \mid \bar{s}\right] \\
& \text { s.t. } \sum_{i} r_{i} \leq R(\bar{s})
\end{aligned}
$$

When terrorists cannot distinguish any differences among targets, optimal behavior implies an even allocation across targets. In this case, private investments in selfprotection change the mean level of self-protection (and, hence, the overall level of terrorist resources), but they have no effects on the syndicate's relative allocation of resources across targets. The substitution effect present in the case of observed protection disappears, and only the wealth effect remains. In this case, a free-rider problem emerges, because no private agent has the incentive to undertake the socially efficient level of self-protective expenditure. This is a source of positive externalities. It applies to certain classes of crime, such as auto theft in the presence of Lojack.

\section{Private Choices and Public Safety}

To understand the impact of negative externalities in self-protection on the behavior of targets, consider an economy with $N$ agents facing a risk of terrorist attack. The $j$-th agent faces risk of experiencing a loss of fixed size $L$ and allocates wealth $W$ between expenditures on insurance coverage $I_{j}$-available at a price $\pi_{j}$ for every dollar of coverage - and on self-protection $s_{j}$. Self-protection is purchased at a per unit price of $k$, and the individually-chosen levels of self-protection jointly determine the probabilities of loss faced by each of the agents. Thus, the probability of loss for $j$ is written as:

$$
p_{j}\left(s_{1}, \ldots, s_{N}\right) .
$$

Agent $j$ 's probability of loss is decreasing in her own chosen level of self protection, but increasing in the levels of self-protection chosen by the other agents. The 
probability of attack satisfies:

$$
\begin{array}{r}
\frac{\partial p_{j}}{\partial s_{j}}=\rho_{s}+\rho_{r} \frac{\partial r_{j}}{\partial s_{j}}<0 \\
\frac{\partial p_{j}}{\partial s_{i}}=\rho_{r} \frac{\partial r_{j}}{\partial s_{i}}>0
\end{array}
$$

Other agents' protection investments influence the probability of attack, because terrorists substitute towards less fortified targets, or $\frac{\partial r_{j}}{\partial s_{i}}>0$. The probability of loss affects the price of insurance, written as:

$$
\pi_{j}\left(s_{1}, \ldots, s_{N} ; \alpha\right) \equiv p_{j}\left(s_{1}, \ldots, s_{N}\right)+\alpha,
$$

where $0 \leq \alpha \leq 1$ reflects other influences on the price of insurance such as administrative expenses, capital costs, and information costs. We will assume that the pricing reflects "real" costs (such as administrative costs or underwriting costs) in the sense that they cannot be avoided by government intervention.

Finally, we include a public good (or bad) influenced by self-protection. We write this as $V\left(s_{1}, \ldots, s_{N}\right)$. The influence of self-protection could be either positive or negative, but the key point is that the public good, which is enjoyed by all, is jointly determined by the individually-chosen levels of self-protection.

\subsection{Private Decisions}

In this environment, agent $j$ solves:

$$
\begin{aligned}
& \max _{s_{j}, I_{j}}\left\{p_{j} U_{0}\left(W-L+\left(1-\pi_{j}\right) I_{j}-k s_{j}\right)+\right. \\
& \left.\left(1-p_{j}\right) U_{1}\left(W-\pi_{j} I_{j}-k s_{j}\right)+V\left(s_{1}, \ldots, s_{N}\right)\right\},
\end{aligned}
$$

where $U_{0}$ and $U_{1}$ are increasing functions representing the utility of wealth in the loss and no-loss states, respectively. If all functions are differentiable, the individual optimality condition for the choice of insurance is the familiar

$$
\pi_{j}=\frac{p_{j} U_{0}^{\prime}}{\left(1-p_{j}\right) U_{1}^{\prime}+p_{j} U_{0}^{\prime}} .
$$

When pricing is actuarially fair $\left(\pi_{j}=p_{j}\right)$, this condition equates marginal utilities across states. The condition for the choice of self-protection may be written as:

$$
\frac{\partial p_{j}}{\partial s_{j}}\left(U_{0}-U_{1}\right)-\left[p_{j} U_{0}^{\prime}+\left(1-p_{j}\right) U_{1}^{\prime}\right]\left(k+\frac{\partial \pi_{j}}{\partial s_{j}} I_{j}\right)+\frac{\partial V}{\partial s_{j}}=0 .
$$


The first term is positive and reflects self-protection's mitigating impact on the probability of loss. The second term reflects the net marginal pecuniary cost of selfprotection, including any premium reductions realized. The last term reflects the marginal impact of the individual's choice on his private valuation of the public good. To illustrate, when the third term is negative, the agent balances the marginal benefit associated with loss prevention (the first term), with the marginal out-of-pocket cost (the second term) and the marginal impairment of the public good (the third term).

We now study how individual choices may be socially inefficient. Consider the social planner's problem, where, for simplicity, the Pareto weights have been equalized across agents:

$$
\begin{aligned}
& \max _{s_{1}, \ldots, s_{N} ; I_{1}, \ldots I_{N}}\left\{\sum _ { j = 1 } ^ { N } \left[p_{j} U_{0}\left(W-L+\left(1-\pi_{j}\right) I_{j}-k s_{j}\right)+\right.\right. \\
& \left.\left.\left(1-p_{j}\right) U_{1}\left(W-\pi_{j} I_{j}-k s_{j}\right)\right]+N V\left(s_{1}, \ldots, s_{N}\right)\right\}
\end{aligned}
$$

This is simply the sum of the utilities of the $N$ agents. The last term is the individual valuation of the public good multiplied by the total number of individuals, representing the total social value of the public good.

The optimality condition for the choice of $I_{j}$ is identical to Equation 3.3 from the individual agent's problem. However, the socially optimal choice for $s_{j}$ is:

$$
\begin{gathered}
\frac{\partial p_{j}}{\partial s_{j}}\left(U_{0 j}-U_{1 j}\right)-\left[p_{j} U_{0 j}^{\prime}+\left(1-p_{j}\right) U_{1 j}^{\prime}\right]\left(k+\frac{\partial \pi_{j}}{\partial s_{j}} I_{j}\right)+\frac{\partial V_{j}}{\partial s_{j}}+\ldots \\
\sum_{i \neq j}\left[\frac{\partial p_{i}}{\partial s_{j}}\left(U_{0 i}-U_{1 i}\right)-\left(p_{i} U_{0 i}^{\prime}+\left(1-p_{i}\right) U_{1 i}^{\prime}\right) \frac{\partial \pi_{i}}{\partial s_{j}} I_{i}+\frac{\partial V_{i}}{\partial s_{j}}\right]=0,
\end{gathered}
$$

where $U_{0 i}$ and $U_{1 i}$ represent agent $i$ 's utility in the loss and no-loss states, respectively. The first three terms (the top line) are simply the individual effects from Equation 3.4. The summation term (the bottom line) includes the three marginal "spillover" effects considered by the social planner but neglected by the individual. This captures the marginal impact of $s_{j}$ on the probabilities of loss for the other agents, any associated changes in insurance prices for other agents, and the marginal impact of $s_{j}$ on the public good values enjoyed by the other agents.

The first and second spillovers concern risk and associated costs. In choosing selfprotection, the individual does not consider any effects on the probabilities of loss faced by other agents and the associated prices of insurance. In the case of terrorism, the cross-effects could be detrimental, in which case the individual overinvests in selfprotection from a social perspective. In the case of Lojack, they could be beneficial, in which case the individual underinvests. The total externality is measured by two components: the direct equilibrium impact of self-protection on the utility of others, 
and the impact on other agents' insurance premiums. In more general terms, selfprotection by one agent encourages others to undertake remedial expenditures, but it may also have a direct impact on others' utility if remedial expenditures are not complete. For example, if individuals are fully insured, the externality consists solely of the increase in remedial expenditures on insurance. Conversely, when there is no terror insurance - and thus no remedial expenditures - the externality consists solely of the direct effect on utility. ${ }^{8}$

The last spillover concerns the public good. In choosing self-protection, the individual does not consider any benefits or costs that accrue to other agents. As an example, consider cautious behavior by a soldier. It is individually rational for a soldier to avoid mortality risk at the margin, but such behavior might jeopardize the nation's chances of winning a war. To take another salient example, self-protection against terrorism by a firm may dictate moving out of downtown areas and avoiding prominent high-rise buildings. However, there may well be public goods associated with the presence of prestigious properties in downtown locales.

The source of the inefficiency becomes particularly clear if we rewrite this condition in terms of the primitive probabilities $\rho$. Substituting in the expressions from Equation 3.1, and using the fact that $\sum_{j=1}^{N} \frac{\partial r_{j}}{\partial s_{i}}=0$ when terrorist resources are fixed, Equation 3.6 becomes:

$$
\frac{\partial \rho_{j}}{\partial s_{j}}\left(U_{0 j}-U_{1 j}\right)-\left[p_{j} U_{0 j}^{\prime}+\left(1-p_{j}\right) U_{1 j}^{\prime}\right]\left(k+\frac{\partial \rho_{j}}{\partial s_{j}} I_{j}\right)+\frac{\partial V_{j}}{\partial s_{j}}=0,
$$

The social planner would like individuals to consider $\frac{\partial \rho_{j}}{\partial s_{j}}$ rather than $\frac{\partial p_{j}}{\partial s_{j}}$. This amounts to taking terrorists' resource allocation decisions as fixed and ignoring the effect of protection on the decisions of terrorists. Social efficiency dictates that agents treat terrorism just like earthquakes, hurricanes, and other risks of loss where the probability of loss is independent of self-protection expenditures.

\subsection{Government Policy}

In this section, we study government policy when it cannot directly control choices, but must instead rely on policies that influence market prices. Since the spillovers are generated by self-protection behavior, that behavior would seem to be the first target for government policy. However, taxes, subsidies, or restrictions aimed at self-protection may not be cost-effective or even feasible.

For example, consider taxes on bank deposit withdrawals or suspensions of deposit convertibility. Both of these policies dissuade depositors from running on banks, but they fail to differentiate between depositors who "need" the money and those who

\footnotetext{
${ }^{8}$ While the change in the insurance premium is, strictly speaking, a pecuniary externality, it reflects an underlying technical (or real) externality, namely the effect of other agents' self-protection. The underlying technical externality has a pecuniary impact and a non-pecuniary impact, and thus its total cost includes both these components.
} 
do not. Thus, the burden of the policy is highest for the least fortunate, making the overall social cost of the policy high. Another example is the case of the soldier. It may be difficult to identify the range of behaviors that qualify as suboptimal selfprotection at the margin. Likewise, self-protection in the case of terrorism entails a wide range of activities - such as beefing up security, avoiding public places, relocation, and emigration - all of which may be difficult to describe and regulate in a policy aimed at promoting the national interest. It may be infeasible to isolate and tax the myriad methods for protecting against terrorism. Even if the government could identify all such methods, it could not account for investments that are more than just anti-terrorist in nature. For instance, dogs that sniff bombs and drugs, or background checks on employees are both ways to protect against terrorism, but they also have a variety of other functions that the government should not be discouraging.

Instead of directly regulating self-protection, the government can subsidize (or tax) insurance purchases. Even if the insurance market itself is functioning efficiently, insurance subsidies can be justified by failures in the market for protection. Another means of regulating private protection is to provide public protective services, such as law enforcement in the case of terrorism, or banking regulations in the case of deposit insurance. If public protection is substitutable with private protection, this can also limit excessive private protection. Even if it is not, however, the government may still find it optimal to provide public protection when it is uniquely positioned to limit the probability of loss for its citizens. In this case, public protective policies would provide an additional impetus for insurance subsidies.

\subsubsection{Insurance Subsidies}

In cases where it is costly or infeasible to tax self-protection, the indirect approach of insurance subsidies may yield the desired results. By encouraging or forcing the purchase of insurance, the government encourages moral hazard and therefore reduces the negative or positive externalities associated with self-protection.

To see this, consider a government that has access to lump-sum taxation $\tau$ in order to subsidize (or tax) insurance prices. The subsidy rate, $f_{j} \equiv f\left(\phi, \pi_{j}\right)$, is controlled by the government through the choice of $\phi$, with $\frac{\partial f}{\partial \phi}>0$ and $0 \leq \frac{\partial f}{\partial \pi_{j}} \leq \phi$. Agent $j$ pays the price $\pi_{j}-f_{j}$. This general specification can accommodate a variety of subsidy schemes. In particular, it allows an "additive" subsidy as in

$$
f\left(\phi, \pi_{j}\right) \equiv \phi,
$$

where the government offers a fixed contribution per unit of coverage purchased. It also supports a "multiplicative" subsidy such as

$$
f\left(\phi, \pi_{j}\right) \equiv \phi \pi_{j}
$$

where the government pays for a fixed fraction of total insurance costs.

Agent $j$ now solves: 


$$
\begin{gathered}
\max _{s_{j}, I_{j}}\left\{p _ { j } U _ { 0 } \left(\left(W-\tau_{j}-L+\left(1-\pi_{j}+f\left(\phi, \pi_{j}\right)\right) I_{j}-k s_{j}\right)+\ldots\right.\right. \\
\left(1-p_{j}\right) U_{1}\left(\left(W-\tau_{j}-\left(\pi_{j}-f\left(\phi, \pi_{j}\right)\right) I_{j}-k s_{j}\right)+V\left(s_{1}, \ldots, s_{N}\right)\right\} .
\end{gathered}
$$

The value of the insurance subsidy as a policy tool will depend on whether or not it discourages self-protection. How will subsidies influence behavior? The answer depends on two conditions. First, insurance and self-protection must be substitutes. In other words, there must be moral hazard: the purchase of more insurance ought to discourage protective investments. Second, the Nash equilibrium across agents must be stable in a sense we will outline below. If not, subsidies may not affect coverage or protection decisions.

Introducing subsidies into Equation 3.3 and Equation 3.4 results in:

$$
\begin{gathered}
\pi_{j}-f\left(\phi, \pi_{j}\right)=\frac{p_{j} U_{0}^{\prime}}{\left(1-p_{j}\right) U_{1}^{\prime}+p_{j} U_{0}^{\prime}} \\
\frac{\partial p_{j}}{\partial s_{j}}\left(U_{0}-U_{1}\right)-\left[p_{j} U_{0}^{\prime}+\left(1-p_{j}\right) U_{1}^{\prime}\right]\left(k+\left(\frac{\partial \pi_{j}}{\partial s_{j}}-f_{\pi} \frac{\partial \pi_{j}}{\partial s_{j}}\right) I_{j}\right)+\frac{\partial V}{\partial s_{j}}=0
\end{gathered}
$$

A budget-balancing subsidy (i.e., one for which $\left.\tau_{j}=f\left(\phi, \pi_{j}\right) I_{j}\right)$ has no impact on consumption. However, it will lower the price of insurance in Equation 3.9 and thus raise the net marginal utility of insurance. If $f_{\pi}>0$ (e.g., if the subsidy is multiplicative), it also lowers the marginal utility of self-protection. When the government pays a share of the insurance premium, the agent realizes a smaller share of the premium reduction associated with investments in self-protection. This weakens incentives for protection. In the case of an additive subsidy, this effect is not present. In either case, a subsidy raises the marginal utility of insurance and weakly lowers the marginal utility of self-protection. These substitution effects will be reinforced if insurance and self-protection are substitutes-i.e., if there is moral hazard. In the presence of moral hazard, therefore, subsidies boost insurance and discourage self-protection.

We identify two sets of conditions - outlined more formally in the appendix - that give rise to moral hazard. In both cases, we employ constant absolute risk aversion (CARA) and $p_{j}<0.5$. The first set of conditions is actuarially fair insurance pricing and a multiplicative subsidy, under which $f\left(\phi, \pi_{j}\right)=\phi \pi_{j}$. Under actuarially fair pricing, the marginal effect of self-protection on the marginal utility of insurance simplifies to $f_{\pi} \frac{\partial p_{j}}{\partial s_{j}}\left(p_{j} U_{0}^{\prime}+\left(1-p_{j}\right) U_{1}^{\prime}\right)$. With an additive subsidy, this is equal to zero, ${ }^{9}$ but with a multiplicative subsidy, it is negative. For example, suppose the

\footnotetext{
${ }^{9}$ Thus, contrary to the findings of Ehrlich and Becker (1972), we find that insurance and selfprotection are independent at the point where pricing is actuarially fair when the relationship between price and self-protection is maintained. This is because we define insurance as coverage, while Ehrlich and Becker define it as coverage minus premium. Since self-protection always lowers the insurance premium, their formulation builds in complementarity at the point of actuarial fairness.
} 
government pays for half the insurance bill. This reduces the agent's incentives to lower her premium bill through self-protection.

Without actuarially fair pricing, it is possible to have moral hazard under more general types of subsidies, including additive subsidies. With unfair pricing, there exists a partially offsetting income effect. Extra expenditures on insurance still substitute for self-protection by narrowing the difference between income in the loss and no-loss states; this lowers the gains to self-protection. However, extra expenditures on insurance also lower income and thus may increase risk aversion; this raises the gain to self-protection. This effect may be particularly significant if the premium and probability of loss are so high that they sum to more than unity. Sufficient conditions for this outcome to be averted are CARA utility (which eliminates the effect of income on risk-aversion) and $\pi_{j}-f<0.5$.

When insurance and self-protection are substitutes, subsidies will encourage insurance and discourage self-protection, but only if the equilibrium across agents is stable in a sense we outline in the appendix. To see why this condition matters, consider a terrorist group that seeks to hit only one of $N$ identical targets, and to hit only the least defended target. ${ }^{10}$ This case has no stable Nash equilibrium with terrorism. Suppose there is one, so that all targets purchase the same levels of insurance and self-protection, and all face the probability $\frac{1}{N}$ of attack. Any one target can lower her attack probability to zero with just an infinitesimal increase in self-protection. Therefore, the only stable equilibrium is one in which there is no probability of attack. In this case, government subsidies cannot alter behavior. ${ }^{11}$ The appendix lists two conditions sufficient to rule this out. Effectively, we require that an individual's own self-protection expenditures have a larger impact on her attack probability than the expenditures of others. Moreover, Proposition 2 in the appendix shows that these two conditions are met when terrorists solve the problem outlined in Section 2.

As the appendix demonstrates in more detail, subsidies encourage insurance, $\frac{\partial I_{j}}{\partial \phi}>$ 0 and discourage self-protection, $\frac{\partial s_{j}}{\partial \phi}<0$ under the circumstances outlined above. The government can then use insurance subsidies as a tool to correct failure in the market for self-protection. Denote the optimal choices of agent $j$ by $I_{j}^{*}$ and $s_{j}^{*}$. The lump sum taxes are fixed in advance of the agent's maximization (i.e., the agent takes these as given), but must be consistent with government budget balance, so that $\tau_{j}=$ $f\left(\phi, \pi_{j}\right) I_{j}$. Define $p_{j}^{*} \equiv p_{j}\left(s_{1}^{*}, \ldots, s_{N}^{*}\right), \pi_{j}^{*} \equiv \pi_{j}\left(s_{1}^{*}, \ldots, s_{N}^{*} ; \alpha ; \phi\right)$ and $V_{j}^{*} \equiv V\left(s_{1}^{*}, \ldots, s_{N}^{*}\right)$. With equal Pareto weights, the government chooses subsidies to solve:

\footnotetext{
${ }^{10}$ This strategy is incompatible with the model of terrorism outlined earlier. It requires the presence of fixed costs of attack that are high enough to cause terrorists to concentrate all their resources on a single target.

${ }^{11}$ An exception occurs if subsidies are so high as to encourage full insurance by every target.
} 


$$
\begin{aligned}
\max _{\phi} & \sum_{j=1}^{N}\left\{p_{j}^{*} U_{0}\left(W-\tau_{j}-L+\left(1-\pi_{j}^{*}+f\left(\phi, \pi_{j}^{*}\right)\right) I_{j}^{*}-k s_{j}^{*}\right)+\ldots\right. \\
& \left.\left(1-p_{j}^{*}\right) U_{1}\left(W-\tau_{j}-\left(\pi_{j}^{*}-f\left(\phi, \pi_{j}^{*}\right)\right) I_{j}^{*}-k s_{j}^{*}\right)+V\left(s_{1}^{*}, \ldots, s_{N}^{*}\right)\right\} .
\end{aligned}
$$

When the budget remains balanced, subsidies have no direct effects on consumption. They operate through effects on insurance and self-protection choices. When the individual chooses insurance and self-protection optimally (given the taxes and subsidies imposed by the government), the government's first order condition simplifies to

$$
\begin{gathered}
\left.-\sum_{j=1}^{N} f_{j} \frac{d I_{j}^{*}}{d \phi}\left[p_{j}^{*} U_{0 j}^{\prime}+\left(1-p_{j}^{*}\right) U_{1 j}^{\prime}\right)\right] \\
\left.-\sum_{j=1}^{N} \frac{\partial f_{j}}{\partial \pi_{j}} \frac{\partial \pi_{j}^{*}}{\partial s_{j}} \frac{d s_{j}^{*}}{d \phi} I_{j}\left[p_{j}^{*} U_{0 j}^{\prime}+\left(1-p_{j}^{*}\right) U_{1 j}^{\prime}\right)\right]+ \\
\sum_{j=1}^{N} \sum_{m \neq j} \frac{d s_{m}^{*}}{d \phi}\left[\frac{\partial p_{j}^{*}}{\partial s_{m}}\left(U_{0 j}-U_{1 j}\right)+\frac{\partial V_{j}^{*}}{\partial s_{m}}-\frac{\partial \pi_{j}^{*}}{\partial s_{m}} I_{j}^{*}\left(p_{j}^{*} U_{0 j}^{\prime}+\left(1-p_{j}^{*}\right) U_{1 j}^{\prime}\right)\right]=0
\end{gathered}
$$

When subsidies are zero, the top two lines are zero and the third line is positive. As a result, some subsidization is always optimal. Intuitively, it is costless to distort an (unsubsidized and) efficient market, so that subsidies are always beneficial initially. This is true even if prices are actuarially fair. ${ }^{12}$

The first term (top line) reflects the marginal cost of distorting the insurance market. Without subsidies, $f_{j}=0$, and this term is zero. As subsidies rise, however, it becomes negative, because the subsidies encourage insurance consumption $\left(\frac{d I_{j}^{*}}{d \phi}>0\right)$. In this case, agents are overconsuming insurance relative to its true marginal cost because they do not consider the effect of their consumption decisions on their tax bill.

Similarly, the second term (middle line) reflects the costs associated with distorting incentives for individual self-protection. If there are no subsidies, or if the price does not affect the subsidy level $\frac{\partial f_{j}}{\partial \pi_{j}}=0$, this term is zero. On the other hand, if there is a subsidy and the subsidy rises in price (as is the case for a multiplicative subsidy), this term will be negative because $\frac{d s_{j}^{*}}{d \phi}<0$. In other words, subsidies that rise with price distort the pecuniary incentives for individuals to self-protect, and this term reflects the effect of that distortion.

\footnotetext{
${ }^{12}$ One possible caveat applies to a case of adverse selection in the insurance market. If adverse selection results in a knife-edge separating equilibrium, it is possible that an infinitesimally small subsidy could break this equilibrium and have adverse consequences for welfare.
} 
The final term (bottom line) reflects the benefit of lowering self-protection when it has external effects. This includes the external effects of others' self-protection on an individual's premium, probability of loss, and the public good. This term is positive if $\frac{\partial p_{j}}{\partial s_{m}}>0, \frac{\partial V_{j}}{\partial s_{m}}<0$, and $\frac{d s_{m}^{*}}{d \phi}<0$. That is, in the case of negative externalities to selfprotection, this term will reflect a benefit, because subsidies limit these externalities.

\subsubsection{Public Protection}

In practice, governments do more to fight terrorism than just intervene in the insurance markets. They develop military and law enforcement strategies to protect their citizens against terror. The linkages among public protection, self-protection, and insurance influence the effectiveness of insurance policy. Even in the presence of public protection though, the optimal policy is likely to involve some level of subsidies for terror insurance, because it is costless (on the margin) to distort a perfectly functioning insurance market. However, insurance subsidies may be either complementary or substitutable with public protection, depending on the technological relationship between public and private protection.

Suppose investments in public protection, $\sigma$, are available at a normalized price of 1 . They lower the probability of loss, but are free from the externalities that characterize private protection. Finally, the cost of public protection is assumed to be spread equally over the $N$ agents in the tax bill, so the government's new budget constraint is now

$$
\tau_{j}=f\left(\phi, \pi_{j}\right)+\frac{\sigma}{N} .
$$

Insurance subsidies remain optimal even in the presence of public protection. The left-hand side of Equation 3.12 gives the marginal utility to the government of insurance subsidies. As discussed earlier, at a zero subsidy level, the first two lines are zero, because it is costless to distort a perfectly functioning market for insurance. The third line is always positive, provided that $\frac{d s_{m}^{*}}{d \phi}<0$, or that subsidies lower self-protection. This will be true under the conditions discussed earlier, ${ }^{13}$ so long as we have an interior solution in private protection. In other words, if targets protect themselves at all, the marginal utility of subsidies is always positive in an unsubsidized equilibrium.

While subsidies are always optimal, it is less clear whether or not they are complementary or substitutable with public protection. To investigate this, we will first examine the relationships among public protection, insurance, and private selfprotection. Under the types of conditions we have been considering, insurance and public protection are substitutes, because increases in public protection make it less risky to go uninsured. To see this, denote the marginal utility of wealth as $\lambda_{j} \equiv p_{j} U_{0}^{\prime}+\left(1-p_{j}\right) U_{1}^{\prime}$ and observe that under a balanced budget constraint,

\footnotetext{
${ }^{13}$ These conditions are: $\pi-f<0.5$, unfair pricing, and CARA utility. Alternatively, we can assume fair insurance pricing, $\pi<0.5$, CARA utility, and $f\left(\phi, \pi_{j}\right)=\phi \pi_{j}$.
} 


$$
\begin{array}{r}
\frac{\partial^{2} U_{j}^{*}}{\partial I \partial \sigma} \equiv \frac{\partial p_{j}^{*}}{\partial \sigma}\left[\left(1-\pi_{j}^{*}-p_{j}^{*}+f\left(\phi, \pi_{j}^{*}\right)+p_{j}^{*} f_{\pi}\right)\left(U_{0 j}^{\prime}-U_{1 j}^{\prime}\right)+\right. \\
\left.f_{\pi} U_{1 j}^{\prime}\right]+\left[\frac{1}{N}+\frac{\partial \pi_{j}^{*}}{\partial \sigma} I_{j}^{*}\right]\left[-\frac{\partial \lambda_{j}}{\partial I}\right]
\end{array}
$$

We will impose the same three conditions as in the previous section: $\pi-f<0.5$, unfair pricing, and CARA utility. Under these assumptions, this expression is negative. Unfair pricing and $\pi-f<0.5$ ensures that the first term is negative. The second term is an income effect that could be positive or negative (or zero), depending on the productivity of public protection. CARA utility ensures that it is zero.

Public and private protection may be either complements or substitutes. Computing the cross-partial between private and public protection reveals that

$$
\begin{aligned}
\frac{\partial^{2} U_{j}^{*}}{\partial s \partial \sigma} & \equiv \\
& \frac{\partial^{2} p_{j}}{\partial s_{j} \partial \sigma}\left(U_{0}-U_{1}\right)-\left[p_{j} U_{0}^{\prime}+\left(1-p_{j}\right) U_{1}^{\prime}\right]\left[\frac{\partial^{2} \pi}{\partial s \partial \sigma} I_{j}\left(1-f_{\pi}\right)+\frac{\partial \pi_{j}}{\partial s_{j}} I_{j}\left(-f_{\pi \pi} \frac{\partial \pi_{j}}{\partial \sigma}\right)\right] \\
& -\left[\frac{\partial p_{j}}{\partial \sigma}\left(U_{0}^{\prime}-U_{1}^{\prime}\right)\right]\left(k+\frac{\partial \pi}{\partial s_{j}}\left(1-f_{\pi}\right) I_{j}\right) \\
& -\left(\frac{1}{N}+\frac{\partial \pi_{j}}{\partial \sigma}\right)\left[\frac{\partial p_{j}}{\partial s_{j}}\left(U_{0}^{\prime}-U_{1}^{\prime}\right)-\left(k+\frac{\partial \pi_{j}}{\partial s_{j}}\left(1-f_{\pi}\right) I_{j}\right)\left(p_{j} U_{0}^{\prime \prime}+\left(1-p_{j}\right) U_{1}^{\prime \prime}\right)\right]
\end{aligned}
$$

For simplicity, suppose that $f_{\pi \pi}=0$, so that the subsidy is at most linear in the premium. (This accommodates a multiplicative or additive subsidy.) The first line represents the technological relationship between public and private protection - the direct impact of public protection investment on the productivity of private protection in reducing the loss probability. The sign of this effect can be positive (if public protection makes private investments more productive at reducing the loss probability) or negative (if the reverse is true). The second line, which is positive, captures an indirect income effect; by reducing the probability of loss, public protection effectively makes the agent richer and more willing to spend on private protection. The third line represents another type of income effect. Spending on private protection affects the marginal utility of wealth, and this affects the marginal cost of spending resources on public protection. The sign of this effect depends on two factors: the form of the utility function, which determines the relationship between self-protection and the marginal utility of wealth; and whether public protection is costly or beneficial in a strictly pecuniary sense. Under CARA utility, self protection has no impact on the marginal utility of wealth and this term is zero. 
If public and private protection are technological complements in reducing the loss probability, Equation 3.14 is positive under CARA utility; public protection would then encourage private protection by making it more productive. The technological effect is positive and reinforced by the indirect income effect (the second line), while the traditional income effect disappears due to CARA utility. The appendix shows that, in this case (along with our assumptions of unfair pricing, $\pi<0.5$, and CARA utility): $\frac{\partial s}{\partial \sigma}>0$, and $\frac{\partial I}{\partial \sigma}<0$.

If, on the other hand, public and private protection are substitutes in reducing the loss probability, the technological effect will be negative, while the indirect income effect is positive. The response of the consumer will then depend on which effect dominates. The appendix proves that, in the case where public and private protection are perfect substitutes, $\frac{\partial s}{\partial \sigma}<0$, and $\frac{\partial I}{\partial \sigma}=0$

These findings have important implications for how subsidies should respond to increases in the efficiency of public protection technology. Include the public protection level $\sigma$ in the equilibrium loss probability and premium, according to $p_{j}^{*} \equiv p_{j}\left(s_{1}^{*}, \ldots, s_{N}^{*} ; \sigma\right)$, and $\pi_{j}^{*} \equiv \pi_{j}\left(s_{1}^{*}, \ldots, s_{N}^{*} ; \alpha ; \sigma\right)$. With equal Pareto weights, the government chooses subsidies and public protection to solve:

$$
\begin{aligned}
\max _{\phi, \sigma} & \sum_{j=1}^{N}\left\{p_{j}^{*} U_{0}\left(W-\tau_{j}-L+\left(1+f\left(\phi, \pi_{j}^{*}\right)-\pi_{j}^{*}\right) I_{j}^{*}-k s_{j}^{*}\right)+\ldots\right. \\
& \left.\left(1-p_{j}^{*}\right) U_{1}\left(W-\tau_{j}-\left(\pi_{j}^{*}-f\left(\phi, \pi_{j}^{*}\right)\right) I_{j}^{*}-k s_{j}^{*}\right)+V\left(s_{1}^{*}, \ldots, s_{N}^{*}\right)\right\} .
\end{aligned}
$$

The first order condition for insurance subsidies is essentially the same as before. Assuming that individuals choose insurance and self-protection optimally, the government's first order condition for public protection simplifies to:

$$
\begin{array}{r}
\sum_{j=1}^{N}\left[\frac{\partial p_{j}^{*}}{\partial \sigma}\left(U_{0 j}-U_{1 j}\right)-\frac{\partial \pi_{j}^{*}}{\partial \sigma}\left(1-f_{\pi}\right) I_{j}^{*}\left(p_{j}^{*} U_{0 j}^{\prime}+\left(1-p_{j}^{*}\right) U_{1 j}^{\prime}\right)\right]+ \\
\sum_{j=1}^{N} \sum_{m \neq j} \frac{d s_{m}^{*}}{d \sigma}\left[\frac{\partial p_{j}^{*}}{\partial s_{m}}\left(U_{0 j}-U_{1 j}\right)+\frac{\partial V_{j}^{*}}{\partial s_{m}}-\frac{\partial \pi_{j}^{*}}{\partial s_{m}}\left(1-f_{\pi}\right) I_{j}^{*}\left(p_{j}^{*} U_{0 j}^{\prime}+\left(1-p_{j}^{*}\right) U_{1 j}^{\prime}\right)\right]+ \\
\sum_{j=1}^{N}\left[\left(-\frac{d \tau}{d \sigma}\right)\left(p_{j}^{*} U_{0 j}^{\prime}+\left(1-p_{j}^{*}\right) U_{1 j}^{\prime}\right)\right]=0
\end{array}
$$

The first line represents the social benefit of reducing the probability of loss through public protection, while the third line represents the pecuniary cost of financing protection. The middle line reflects the impact of public protection on private protection decisions. If public and private protection are complements, this is a cost: public 
protection worsens externalities in private protection. However, if public protection is sufficiently productive, the benefits can overcome the costs. In other words, there can be public protection, even if it worsens these externalities. In this case, increases in public protection worsen externalities and thus increase the productivity of subsidizing insurance in order to limit them.

On the other hand, when public protection makes private protection less productive $\left(\frac{\partial^{2} p}{\partial s \partial \sigma}>0\right)$, public protection may discourage private protection $\left(\frac{\partial s}{\partial \sigma}<0\right)$. Public protection then has the added benefit of reducing externalities in private protection. As a result, additional public protection limits protective externalities and makes insurance subsidies less productive. In other words, it functions as a substitute for insurance subsidies. Both are policy techniques that can be used to discourage selfprotection. Insurance premium subsidies accomplish the task indirectly by encouraging higher levels of insurance purchase and thus lowering the gains to self-protection, while public protection expenditures are direct substitutes for private protection.

Public protection and insurance subsidies may be complementary in other circumstances, even in the absence of any strong relationship between public and private protection. For example, consider the case where the government pays for all insurance premiums to the point of full insurance. In this case, all agents fully insure and set private protection to zero. In this case, neither insurance nor private protection respond to changes in public protection, but it may still be optimal for the government to provide public protection in order to reduce the tax bill. Mathematically, Equation 3.16 reduces to

$$
\sum_{j=1}^{N}\left(p_{j}^{*} U_{0 j}^{\prime}+\left(1-p_{j}^{*}\right) U_{1 j}^{\prime}\right)\left[-\frac{\partial \pi_{j}^{*}}{\partial \sigma} I_{j}^{*}-\frac{1}{N}\right]=0,
$$

a marginal utility weighted average balancing of the marginal pecuniary cost of public protection, $\frac{1}{N}$, with its marginal premium reduction benefit, $-\frac{\partial \pi_{j}^{*}}{\partial \sigma} I_{j}^{*}$.

This example, though extreme, illuminates another sense in which public protection and insurance subsidies can be complements. Insurance subsidies can mitigate private incentives for premium reductions while simultaneously increasing the government's share of insurance premiums. As this share rises, the government is faced with increased incentives for reducing insurance premiums, and public protection accomplishes such a reduction.

In general, the government will find it optimal to mix subsidies and public protection according to their cost-efficiency in reducing private protection and according to their level of complementarity. Changes in the efficiency of public protection can be expected to affect the optimal mix according to the relationship between public protection and private protection. When public protection and private protection are substitutes, changes in the efficiency of public protection-manifested by an increase in $\frac{\partial p}{\partial \sigma}$ - would cause an increase in public protection, but a decrease in subsidies. On the other hand, if public and private protection are complements, the same increase 
in efficiency might result in more subsidies, not less. In the latter case, subsidies are used in part to counteract the ill effects of public protection on the market for private protection.

\section{Conclusion}

Insurance and protection against terrorism - like insurance against crime or war - is distinguished by its influence on the behavior of terrorists and thus on the probability of loss. This creates externalities in the market for protection. A terrorist group can create negative externalities in protection that call for government insurance subsidies, just by pursuing its own objectives rationally. These subsidies are still optimal even in the presence of public law enforcement strategies.

This paper argues that, if the U.S. federal government does decide to subsidize terrorism insurance, the primary motivation will likely have been these externalities. Indeed, the capital market frictions emphasized in this and other catastrophe markets (see, e.g., Froot, 1997) may be the catalyst for government action, but the distinguishing feature of the terrorism insurance market - and the feature that may ultimately trigger the enactment of subsidies - is the external effects associated with self protection. A construction project foundering in Manhattan due to lack of affordable terrorism insurance coverage may be seen as a national public policy issue, while similar foundering associated with windstorm or earthquake insurance coverage is not. The framework of this paper can be used to interpret terrorism insurance subsidies as a strategy of influencing behavior in the context of a war effort. In this light, government-sponsored terrorism insurance appears to have more in common with warrisk life insurance (government insurance provided to soldiers) or propaganda (which discourages behavior likely to generate negative externalities, and vice-versa) than with programs aimed at remedying the problems in catastrophe insurance markets (such as the National Flood Insurance Program).

Although the main focus of this paper was the terrorism insurance market, the paper's ideas need not be so limited in their application. To illustrate the extension of the ideas, we have highlighted deposit insurance and banking regulation as an example of insurance subsidies and public protection working in tandem, with the former a policy specifically aimed at discouraging self-protective behavior. Going further, it seems likely that the government's policy of subsidization in other insurance markets - such as health insurance - may also have behavioral goals that have remained largely unexplored by economists. This seems a fruitful area for future research. 


\section{Mathematical Appendix}

The individual chooses insurance and self-protection to maximize the objective function discussed in the text:

$$
\begin{aligned}
Q \equiv & p_{j} U_{0}\left(W-L-\tau_{j}+\left(1+f\left(\phi, \pi_{j}\right)-\pi_{j}\right) I_{j}-k s_{j}\right)+ \\
& \left(1-p_{j}\right) U_{1}\left(W-\tau_{j}+\left(f\left(\phi, \pi_{j}\right)-\pi_{j}\right) I_{j}-k s_{j}\right)+V_{j}
\end{aligned}
$$

This is subject to the budget-balancing constraint:

$$
\tau_{j}=f\left(\phi, \pi_{j}\right) I_{j}
$$

The problem in Equation A.1 has the following two first order conditions:

$$
\begin{gathered}
Q_{s_{j}}=\frac{\partial p_{j}}{\partial s_{j}}\left[U_{0}-U_{1}\right]-\left[p_{j} U_{0}^{\prime}+\left(1-p_{j}\right) U_{1}^{\prime}\right]\left(k+I_{j}\left(\frac{\partial \pi_{j}}{\partial s_{j}}-f_{\pi} \frac{\partial \pi_{j}}{\partial s_{j}}\right)\right)+V_{s_{j}}=0 \\
Q_{I_{j}}=p_{j} U_{0}^{\prime}\left(1+f\left(\phi, \pi_{j}\right)-\pi_{j}\right)-\left(1-p_{j}\right) U_{1}^{\prime}\left(\pi-f\left(\phi, \pi_{j}\right)\right)=0
\end{gathered}
$$

The second derivatives are given by:

$$
\begin{gathered}
Q_{I_{j} I_{j}}=p U_{0}^{\prime \prime}(1+f-\pi)^{2}+(1-p) U_{1}^{\prime \prime}(\pi-f)^{2} \\
Q_{s_{j} s_{j}}=\frac{\partial^{2} p_{j}}{\partial s_{j} \partial s_{j}}\left[U_{0}-U_{1}\right]-2 \frac{\partial p_{j}}{\partial s_{j}}\left[U_{0}^{\prime}-U_{1}^{\prime}\right]\left(k+I_{j} \frac{\partial \pi_{j}}{\partial s_{j}}\left(1-f_{\pi}\right)\right)+V_{s_{j} s_{j}} \\
+\left(p U_{0}^{\prime \prime}+(1-p) U_{1}^{\prime \prime}\right)\left(k+I_{j} \frac{\partial \pi_{j}}{\partial s_{j}}\left(1-f_{\pi}\right)\right)^{2}-\lambda_{j} I_{j}\left[\frac{\partial^{2} \pi_{j}}{\partial s_{j} \partial s_{j}}\left(1-f_{\pi}\right)-f_{\pi \pi}\left(\frac{\partial \pi_{j}}{\partial s_{j}}\right)^{2}\right]
\end{gathered}
$$

It is also useful to calculate the cross-partial of $Q$.

$$
\begin{aligned}
& Q_{s_{j} I_{j}}=\frac{\partial p_{j}}{\partial s_{j}}\left(U_{0}^{\prime}-U_{1}^{\prime}\right)\left(f\left(\phi, \pi_{j}\right)-\pi_{j}\right)+\frac{\partial p_{j}}{\partial s_{j}} U_{0}^{\prime}-\frac{\partial \pi_{j}}{\partial s_{j}}\left(1-f_{\pi}\right) \lambda_{j}- \\
&\left(k+\frac{\partial \pi_{j}}{\partial s_{j}}\left(1-f_{\pi}\right) I_{j}\right)\left[p_{j} U_{0}^{\prime \prime}\left(1+f\left(\phi, \pi_{j}\right)-\pi_{j}\right)+\left(1-p_{j}\right) U_{1}^{\prime \prime}\left(f\left(\phi, \pi_{j}\right)-\pi_{j}\right)\right]
\end{aligned}
$$

The term $\lambda_{j} \equiv p_{j} U_{0}^{\prime}+\left(1-p_{j}\right) U_{1}^{\prime}$ represents the marginal utility of wealth.

Before proceeding with comparative statics, we must verify that the second order conditions hold. The fulfillment of the second order conditions turns out to depend on the "curvature" of the loss probability function relative to the curvature of the utility function. The following proposition identifies some conditions sufficient for the first order conditions to represent a maximum. 
Proposition 1 Let $p$ be decreasing and convex and $U$ be a CARA utility function with coefficient of absolute risk aversion given by $\mu$. Let $Z=\frac{p^{\prime \prime}}{p^{\prime}}$ and $Y=\frac{p^{\prime}}{p}$, with $\mu=$ $|Y| \leq|Z|$. If, in addition, subsidized prices are weakly unfair, $f_{\pi \pi}=0, V=0, k=1$, and $\pi<0.5$, the second order conditions are satisfied.

Proof: The SOC are satisfied if (a) $Q_{I_{j} I_{j}}<0$, (b) $Q_{s_{j} s_{j}}<0$, and (c) $Q_{I_{j} I_{j}} Q_{s_{j} s_{j}}-$ $\left(Q_{s_{j} I_{j}}\right)^{2}>0$. Inspection of Equation A.5 reveals that (a) is satisfied. To see that (b) is satisfied, use the assumptions above, together with the fact that $\pi^{\prime}=p^{\prime}$, to write Equation A.6 as:

$$
Q_{s_{j} s_{j}}=Z\left(p_{j}^{\prime}\left[U_{0 j}-U_{1 j}\right]-\lambda p_{j}^{\prime}\left(1-f_{\pi}\right) I_{j}\right)+\mu \lambda_{j}\left(k+I_{j} p_{j}^{\prime}\left(1-f_{\pi}\right)\right)^{2}
$$

or

$$
Q_{s_{j} s_{j}}=Z \lambda_{j} k+\mu \lambda_{j}\left(k+I_{j} p_{j}^{\prime}\left(1-f_{\pi}\right)\right)^{2}
$$

Since $0<\left(k+I_{j} p^{\prime}\left(1-f_{\pi}\right)\right)<k=1$ and $-Z \geq \mu, Q_{s_{j} s_{j}}<0$.

To see that (c) is satisfied, use CARA utility and Equation A.4) to write Equation A.5 as

$$
Q_{I_{j} I_{j}}=-\mu \lambda_{j}\left(1+f-\pi_{j}\right)\left(\pi_{j}-f\right) .
$$

Similarly, use Equation A.4 to write Equation A.7 as

$$
Q_{s_{j} I_{j}}=Y \lambda_{j}\left[\frac{\left(1+f-\pi_{j}\right)\left(\pi_{j}-f\right)}{\left(1-p_{j}\right)}-p_{j}\left(1-f_{\pi}\right)\right] .
$$

Next, solve for $\varepsilon_{j}=I_{j} p_{j}^{\prime}\left(1-f_{\pi}\right)$. From Equation A.3,

$$
\frac{p^{\prime}\left[U_{0}-U_{1}\right]}{\lambda_{j}}-k=\varepsilon_{j},
$$

which simplifies to

$$
\varepsilon_{j}=-\frac{Y}{\mu}\left(\frac{p\left[U_{0}^{\prime}-U_{1}^{\prime}\right]}{\lambda_{j}}\right)-k=\left(\frac{\pi_{j}-f-p_{j}}{\left(1-p_{j}\right)}\right)-k .
$$

So, we can now write:

$$
\begin{gathered}
Q_{I_{j} I_{j}} Q_{s_{j} s_{j}}>\mu^{2} \lambda_{j}^{2}\left(\pi_{j}-f\right)\left(1+f-\pi_{j}\right)\left[k-\left(k+\varepsilon_{j}\right)\right]^{2} \\
\left(Q_{s_{j} I_{j}}\right)^{2}<\mu^{2} \lambda_{j}^{2}\left[\frac{\left(1+f-\pi_{j}\right)\left(\pi_{j}-f\right)}{\left(1-p_{j}\right)}\right]^{2}
\end{gathered}
$$

Some algebra shows that

$$
Q_{I_{j} I_{j}} Q_{s_{j} s_{j}}-\left(Q_{s_{j} I_{j}}\right)^{2}>0 \Longleftrightarrow p<0.5 . \quad \text { QED. }
$$


Even if the second order conditions hold, comparative statics are complicated by the interactions among the agents. We must consider these interactions when determining how a change in an underlying parameter - such as the level of the subsidywill affect individual behavior. To do this, we study a symmetric equilibrium where all agents have the same preferences, make identical choices, and face the same prices, loss probabilities, subsidies, and taxes. Furthermore, we impose additional restrictions on the relationship between the probability of loss and agent actions. Specifically, as delineated in Proposition 3, we require that $\left|\frac{\partial p_{j}}{\partial s_{j}}\right|>\left|\sum_{k \neq j} \frac{\partial p_{j}}{\partial s_{k}}\right|$ and $\frac{\partial}{\partial s_{j}}\left[\frac{\frac{\partial p_{j}}{\partial s_{j}}}{\sum_{k \neq j} \frac{\partial p_{j}}{\partial s_{k}}}\right]>0$.

Are these restrictions reasonable? To shed more light on what they mean, consider the terrorist problem outlined in Equation 2.1. In the following proposition, we show that both restrictions are plausible. The first restriction is a direct implication of terrorist maximization in a symmetric setting under standard regularity conditions. The second restriction depends, in part, on third derivatives of the loss probability function; if these terms are sufficiently small relative to the second and first order effects, the second restriction will hold. To illustrate this, we assume that the third derivatives are zero in the following proposition.

Proposition 2 Suppose terrorists solve Equation 2.1, with fixed $R, \rho_{s}<0, \rho_{r}>0$, $\rho_{r r}<0, \rho_{s s}>0, \rho_{s r}<0$, and $s_{i}=s_{j}$ observed $\forall i, j$. Let $p_{j}=\rho\left(s_{j}, r_{j}\right)$. Then, $\left|\frac{\partial p_{j}}{\partial s_{j}}\right|>\left|\sum_{k \neq j} \frac{\partial p_{j}}{\partial s_{k}}\right|$. Suppose, in addition, that $\rho_{s}$ and $p_{s r}$ are bounded from below, $\rho_{r}$ and $\rho_{s s}$ are bounded away from zero, and all third partials of $\rho$ are zero. Then, for sufficiently large $N, \frac{\partial}{\partial s_{j}}\left[\frac{\frac{\partial p_{j}}{\partial s_{j}}}{\sum_{k \neq j} \frac{\partial p_{j}}{\partial s_{k}}}\right]>0$.

Proof: Rewrite the maximization problem as

$$
\max _{\left\{r_{i}\right\}}\left\{\sum_{i=1}^{N-1} \rho\left(s_{i}, r_{i}\right)+\rho\left(s_{N}, R-\sum_{i=1}^{N-1} r_{i}\right)\right\} .
$$

This leads to the first order conditions

$$
\rho_{r}^{i}-\rho_{r}^{N}=0 \quad i=1, \ldots, N-1 .
$$

The Hessian is given by:

$$
H=\left[\begin{array}{ccccc}
\rho_{r r}^{1}+\rho_{r r}^{N} & \rho_{r r}^{N} & . & . & \rho_{r r}^{N} \\
\rho_{r r}^{N} & \rho_{r r}^{2}+\rho_{r r}^{N} & & & \rho_{r r}^{N} \\
\cdot & & \cdot & & \cdot \\
\cdot & & & \cdot & \cdot \\
\cdot & & & \cdot & \cdot \\
\rho_{r r}^{N} & \rho_{r r}^{N} & \cdot & \cdot & \cdot \\
\rho_{r r}^{N-1}+\rho_{r r}^{N}
\end{array}\right]
$$


where the superscripts indicate the subscript of the first argument in the probability function (i.e., $\left.\rho_{r r}^{1}=\rho_{r r}\left(s_{1}, r_{1}\right)\right)$. Evidently, for all $i$ and $j, \rho_{r r}^{i}=\rho_{r r}^{j}=\rho_{r r}<0$. It is then easy to verify that the second order conditions for a maximum hold.

The determinant of $H$ can be calculated as $N\left(\rho_{r r}\right)^{N-1}$. A simple exercise in comparative statics reveals that

$$
\frac{\partial r_{1}}{\partial s_{1}}=\frac{1}{N\left(\rho_{r r}\right)^{N-1}}\left|\begin{array}{cccccc}
-\rho_{s r} & \rho_{r r} & . & \cdot & \cdot & \rho_{r r} \\
0 & 2 \rho_{r r} & \rho_{r r} & \cdot & \cdot & \rho_{r r} \\
\cdot & \rho_{r r} & 2 \rho_{r r} & & \cdot \\
\cdot & \cdot & & \cdot & . \\
\cdot & \cdot & & & \cdot & \cdot \\
0 & \rho_{r r} & . & . & \cdot & 2 \rho_{r r}
\end{array}\right|=\frac{-\rho_{s r}(N-1)}{\rho_{r r} N}=\frac{\partial r_{i}}{\partial s_{i}}, \quad \forall i
$$

Similarly,

$$
\frac{\partial r_{i}}{\partial s_{j}}=\frac{\rho_{s r}}{\rho_{r r} N}, \forall i, j \neq i
$$

We can then write

$$
\begin{gathered}
\frac{\partial p_{i}}{\partial s_{i}}=\frac{\partial \rho^{i}}{\partial s_{i}}+\frac{\partial \rho^{i}}{\partial r_{i}} \frac{\partial r_{i}}{\partial s_{i}} \\
\frac{\partial p_{i}}{\partial s_{j}}=\frac{\partial \rho^{i}}{\partial r_{i}} \frac{\partial r_{i}}{\partial s_{j}}
\end{gathered}
$$

Evidently,

$$
\sum_{j \neq i} \frac{\partial \rho^{i}}{\partial r_{i}} \frac{\partial r_{i}}{\partial s_{j}}=-\frac{\partial \rho^{i}}{\partial r_{i}} \frac{\partial r_{i}}{\partial s_{i}} \Longrightarrow\left|\frac{\partial p_{i}}{\partial s_{i}}\right|>\left|\sum_{j \neq i} \frac{\partial p_{i}}{\partial s_{j}}\right| .
$$

Moving on, note that

$$
\frac{\partial}{\partial s_{j}}\left[\frac{\frac{\partial p_{j}}{\partial s_{j}}}{\sum_{k \neq j} \frac{\partial p_{j}}{\partial s_{k}}}\right]=\frac{\frac{\partial^{2} p_{j}}{\partial s_{j} \partial s_{j}} \sum_{k \neq j} \frac{\partial p_{j}}{\partial s_{k}}-\frac{\partial p_{j}}{\partial s_{j}} \sum_{k \neq j} \frac{\partial^{2} p_{j}}{\partial s_{j} \partial s_{k}}}{\left(\sum_{k \neq j} \frac{\partial p_{j}}{\partial s_{k}}\right)^{2}} .
$$

To determine the value of this expression, we calculate

$$
\begin{aligned}
\frac{\partial^{2} p_{j}}{\partial s_{j} \partial s_{j}} & =\rho_{s s}+2 \rho_{s r} \frac{\partial r_{j}}{\partial s_{j}}+\frac{\partial^{2} p_{j}}{\partial r_{j} \partial r_{j}}\left(\frac{\partial r_{j}}{\partial s_{j}}\right)^{2}+\rho_{r} \frac{\partial^{2} r_{j}}{\partial s_{j} \partial s_{j}} \\
\frac{\partial^{2} p_{j}}{\partial s_{j} \partial s_{k}} & =\rho_{s r} \frac{\partial r_{j}}{\partial s_{k}}+\frac{\partial^{2} p_{j}}{\partial r_{j} \partial r_{j}}\left(\frac{\partial r_{j}}{\partial s_{j}}\right)\left(\frac{\partial r_{j}}{\partial s_{k}}\right)+\rho_{r} \frac{\partial^{2} r_{j}}{\partial s_{j} \partial s_{k}}
\end{aligned}
$$


The proposition is proven if the numerator of Equation A.12 is positive. Using Equations A.8, A.9, A.10, A.11, A.13, and A.14, we write the numerator as

$$
\begin{array}{r}
{\left[\rho_{s s}-\frac{(N+1)}{N} \frac{(N-1)}{N} \frac{\left(\rho_{s r}\right)^{2}}{\rho_{r r}}\right]\left(\rho_{r} \frac{\rho_{s r}}{\rho_{r r}} \frac{(N-1)}{N}\right)-} \\
{\left[\frac{1}{N} \frac{\left(\rho_{s r}\right)^{2}}{\rho_{r r}} \frac{(N-1)}{N}\right]\left(\rho_{s}-\rho_{r} \frac{\rho_{s r}}{\rho_{r r}} \frac{(N-1)}{N}\right),}
\end{array}
$$

where we have noted that the last terms in both Equations A.13 and A.14 are zero, as they depend only on third derivatives of $\rho$. Furthermore, Equation A.15 $>0$ reduces to

$$
\rho_{s s}-\frac{(N-1)}{N} \frac{\left(\rho_{s r}\right)^{2}}{\rho_{r r}}-\frac{1}{N} \frac{\rho_{s}}{\rho_{r}} \rho_{s r}>0
$$

Since $\left|\frac{\rho_{s}}{\rho_{r}} \rho_{s r}\right|$ is bounded and $\rho_{s s}$ is positive and bounded away from zero, the preceding condition holds for sufficiently large $N$. Therefore, $\frac{\partial}{\partial s_{j}}\left[\frac{\frac{\partial p_{j}}{\partial s_{j}}}{\sum_{k \neq j} \frac{\partial p_{j}}{\partial s_{k}}}\right]>0$. QED.

Proposition 3 If $\left|\frac{\partial p_{j}}{\partial s_{j}}\right|>\left|\sum_{k \neq j} \frac{\partial p_{j}}{\partial s_{k}}\right|, \frac{\partial}{\partial s_{j}}\left[\frac{\frac{\partial p_{j}}{\partial s_{j}}}{\sum_{k \neq j} \frac{\partial p_{j}}{\partial s_{k}}}\right]>0, C A R A$ utility, and $V=0$, then $\operatorname{sign}\left(\frac{d s_{j}}{d \phi}\right)=\operatorname{sign}\left(\left.\frac{d s_{j}}{d \phi}\right|_{s_{k}}\right)$, and $\operatorname{sign}\left(\frac{d I_{j}}{d \phi}\right)=-\operatorname{sign}\left(\frac{d s_{j}}{d \phi}\right)$.

Proof: We can decompose the first-order effects of subsidies as follows:

$$
\begin{aligned}
Q_{s_{j} \phi} & =\left.Q_{s_{j} \phi}\right|_{s_{k}}+\sum_{k \neq j} Q_{s_{j} s_{k}} \frac{d s_{k}}{d \phi} \\
Q_{I_{j} \phi} & =\left.Q_{I_{j} \phi}\right|_{s_{k}}+\sum_{k \neq j} Q_{I_{j} s_{k}} \frac{d s_{k}}{d \phi}
\end{aligned}
$$

Computing $\frac{d s_{j}}{d \phi}$ and applying these identities yields the expression:

$$
\frac{d s_{j}}{d \phi}\left(1+\frac{\sum_{k \neq j}\left(Q_{s_{j} s_{k}} Q_{I_{j} I_{j}}-Q_{I_{j} s_{k}} Q_{s_{j} I_{j}}\right)}{D}\right)=\left.\frac{d s_{j}}{d \phi}\right|_{s_{k}}
$$

$D$ is the determinant of the Hessian matrix. To prove $\operatorname{sign}\left(\frac{d s_{j}}{d \phi}\right)=\operatorname{sign}\left(\left.\frac{d s_{j}}{d \phi}\right|_{s_{k}}\right)$, it suffices to show that the term in parentheses is positive. To begin, observe the following equivalence: 


$$
Q_{s_{j}} \equiv\left[\frac{\frac{\partial p_{j}}{\partial s_{j}}}{\sum_{k \neq j} \frac{\partial p_{j}}{\partial s_{k}}}\left(\sum_{k \neq j} Q_{s_{k}}-V_{s_{k}}\right)\right]+V_{s_{j}}-\lambda_{j} k
$$

where $\lambda_{j}$ is the marginal utility of wealth. Differentiating this equivalence, and observing that $\lambda_{j}$ is independent of $I_{j}$ and $s_{j}$ under CARA utility and $V=0$, we obtain:

$$
\begin{gathered}
Q_{s_{j} s_{j}}=\left[\frac{\partial}{\partial s_{j}}\left(\frac{\frac{\partial p_{j}}{\partial s_{j}}}{\sum_{k \neq j} \frac{\partial p_{j}}{\partial s_{k}}}\right)\right] \sum_{k \neq j} Q_{s_{k}}+\frac{\frac{\partial p_{j}}{\partial s_{j}}}{\sum_{k \neq j} \frac{\partial p_{j}}{\partial s_{k}}} \sum_{k \neq j} Q_{s_{k} s_{j}} \\
Q_{s_{j} I_{j}}=\frac{\frac{\partial p_{j}}{\partial s_{j}}}{\sum_{k \neq j} \frac{\partial p_{j}}{\partial s_{k}}} \sum_{k \neq j} Q_{s_{k} I_{j}}
\end{gathered}
$$

Using the above two expressions, we can derive:

$$
\begin{array}{r}
\frac{Q_{I_{j} I_{j}} \sum_{k \neq j} Q_{s_{j} s_{k}}-Q_{s_{j} I_{j}} \sum_{k \neq j} Q_{I_{j} s_{k}}}{D}= \\
\frac{\sum_{k \neq j} \frac{\partial p_{j}}{\partial s_{k}}}{\frac{\partial p_{j}}{\partial s_{j}}}-\frac{Q_{I_{j} I_{j}} \sum_{k \neq j} Q_{s_{k}} \frac{\sum_{k \neq j} \frac{\partial p_{j}}{\partial s_{k}}}{\frac{\partial p_{j}}{\partial s_{j}}}\left[\frac{\partial}{\partial s_{j}}\left(\frac{\frac{\partial p_{j}}{\partial s_{j}}}{\sum_{k \neq j} \frac{\partial p_{j}}{\partial s_{k}}}\right)\right]}{D}
\end{array}
$$

Using the conditions that $\left|\frac{\partial p_{j}}{\partial s_{j}}\right|>\left|\sum_{k \neq j} \frac{\partial p_{j}}{\partial s_{k}}\right|$, and $\frac{\partial}{\partial s_{j}}\left[\frac{\frac{\partial p_{j}}{\partial s_{j}}}{\sum_{k \neq j} \frac{\partial p_{j}}{\partial s_{k}}}\right]>0$, it is straightforward to show that this expression exceeds -1 . This proves $\operatorname{sign}\left(\frac{d s_{j}}{d \phi}\right)=\operatorname{sign}\left(\left.\frac{d s_{j}}{d \phi}\right|_{s_{k}}\right)$.

To prove that $\operatorname{sign}\left(\frac{d I_{j}}{d \phi}\right)=-\operatorname{sign}\left(\frac{d s_{j}}{d \phi}\right)$, observe from Equation A.19 that $\left|\frac{\partial^{2} Q}{\partial s_{j}^{2}}\right|>$ $\left|\sum_{k \neq j} \frac{\partial^{2} Q}{\partial s_{j} \partial s_{k}}\right|$. This implies that $\frac{d s}{d \phi} \sum_{k} \frac{\partial^{2} Q}{\partial s_{j} \partial s_{k}}<0$. Therefore, $\frac{d s}{d \phi} \sum_{k=1}^{N} Q_{s_{j} s_{k}}<0$. As a result, if $\frac{d s}{d \phi}>0$, the change in self-protection levels will lower $Q_{s_{j}}$. Since a budget-balancing subsidy has the direct effect of weakly lowering $Q_{s_{j}}$, the only way for the individual to remain at her optimal level of self-protection is for her to lower insurance and thus boost $Q_{s_{j}}$ in response. Similarly, if $\frac{d s}{d \phi}<0$, the resulting change in self-protection levels will raise $Q_{s_{j}}$ and necessitate an offsetting increase in $I_{j}$. QED

Corollary 3.1 Under the conditions of Proposition 3, $\operatorname{sign}\left(\frac{d s_{j}}{d \sigma}\right)=\operatorname{sign}\left(\left.\frac{d s_{j}}{d \sigma}\right|_{s_{k}}\right)$, and $\operatorname{sign}\left(\frac{d I_{j}}{d \sigma}\right)=-\operatorname{sign}\left(\frac{d s_{j}}{d \sigma}\right)$. 
Proof. The proof of $\operatorname{sign}\left(\frac{d s_{j}}{d \sigma}\right)=\operatorname{sign}\left(\left.\frac{d s_{j}}{d \sigma}\right|_{s_{k}}\right)$ is identical to the one in the proposition, if we replace $\phi$ with $\sigma$. To prove the second result, observe from Equation A.20 that $\left|\frac{\partial^{2} Q}{\partial s_{j} \partial I_{j}}\right|>\left|\sum_{k \neq j} \frac{\partial^{2} Q}{\partial I_{j} \partial s_{k}}\right|$. Therefore, $\frac{d s}{d \sigma} \sum_{k=1}^{N} Q_{I_{j} s_{k}}<0$. As a result, if $\frac{d s}{d \sigma}>0$, the change in self-protection levels will lower $Q_{I_{j}}$. Recall from the text that $Q_{I_{j} \sigma}<0$. Therefore, the change in $\sigma$ will also lower $Q_{I_{j}}$. The only way for the individual to remain at an optimal level of insurance is to lower $I_{j}$ in response. Similarly, if $\frac{d s}{d \sigma}<0$, equilibrium requires that $I_{j}$ rises. QED

Proposition 4 Assume $0.5>\pi-f>p, f_{\phi \pi} \geq 0, C A R A$ utility, and the conditions of Proposition 1 hold. Then $\left.\frac{d s_{j}}{d \phi}\right|_{s_{k}}<0$ and $\left.\frac{d I_{j}}{d \phi}\right|_{s_{k}}>0$.

Proof. With $0.5>\pi>p, \frac{\partial \pi}{\partial s}=\frac{\partial p_{j}}{\partial s}$, and CARA utility, $Q_{s_{j} I_{j}}<0$. To see this, observe first that $\frac{\partial p_{j}}{\partial s_{j}}\left(U_{0}^{\prime}-U_{1}^{\prime}\right)\left(f\left(\phi, \pi_{j}\right)-\pi\right)+\frac{\partial p_{j}}{\partial s_{j}} U_{0}^{\prime}-\frac{\partial \pi}{\partial s_{j}}\left(1-f_{\pi}\right) \lambda<0$, provided that $\frac{\partial \pi}{\partial s}=\frac{\partial p_{j}}{\partial s}$, and $\pi+p<1$. In the last term, $\left(k+\frac{\partial \pi}{\partial s_{j}}\left(1-f_{\pi}\right) I_{j}\right)>0$, because $U_{0}<U_{1}$. CARA utility guarantees that the final term in parentheses (which equals $\left.\frac{d \lambda_{j}}{d I_{j}}\right)$ is zero.

Under a balanced budget constraint, we have the relationships $\left.Q_{I_{j} \phi}\right|_{s_{k}}=f_{\phi} \lambda_{j}>0$, and $\left.Q_{s_{j} \phi}\right|_{s_{k}}=f_{\phi \pi} \frac{\partial \pi_{j}}{\partial s_{j}} \lambda_{j} \leq 0$. Therefore, standard comparative statics arguments imply that:

$$
\begin{aligned}
\left.\frac{d s_{j}}{d \phi}\right|_{s_{k}} & =\frac{-Q_{I_{j} I_{j}} Q_{s_{j} \phi}+Q_{I_{j} \phi} Q_{I_{j} s_{j}}}{D} \\
\left.\frac{d I_{j}}{d \phi}\right|_{s_{k}} & =\frac{-Q_{I_{j} \phi} Q_{s_{j} s_{j}}+Q_{I_{j} s_{j}} Q_{s_{j} \phi}}{D}
\end{aligned}
$$

where $D$ is the (positive, by virtue of Proposition 1) determinant of the Hessian matrix. Evidently, $\left.\frac{d s_{j}}{d \phi}\right|_{s_{k}}$ is strictly negative, and $\left.\frac{d I_{j}}{d \phi}\right|_{s_{k}}$ is strictly positive. QED

Corollary 4.1 Under the conditions of Propositions 1, 2, and 4, $\frac{d s_{j}}{d \phi}<0$, and $\frac{d I_{j}}{d \phi}>$ 0 .

Proof. Under the conditions of CARA utility, $\pi>p$, and $\pi+p<1$, Proposition 4 implies that $\left.\frac{d s_{j}}{d \phi}\right|_{s_{k}}<0$, and $\left.\frac{d I_{j}}{d \phi}\right|_{s_{k}}>0$. The strategic equilibrium conditions and Proposition 3 then imply that $\frac{d s_{j}}{d \phi}<0$ and $\frac{d I_{j}}{d \phi}>0$. QED

Proposition 5 If $\pi-f=p, \pi<0.5, C A R A$ utility, the conditions of Proposition 1 hold, and $f\left(\phi, \pi_{j}\right)=\phi \pi_{j}$, then $\left.\frac{d s_{j}}{d \phi}\right|_{s_{k}}<0$ and $\left.\frac{d I_{j}}{d \phi}\right|_{s_{k}}>0$.

Proof. With fair pricing, $Q_{s_{j} I_{j}}=\lambda f_{\pi} \frac{\partial p_{j}}{\partial s_{j}}$. With a multiplicative subsidy, this expression is strictly negative. Equations A.22 and A.23 then imply the results. QED 
Corollary 5.1 Under the conditions of Proposition 1, 2, and 5, $\frac{d s_{j}}{d \phi}<0$, and $\frac{d I_{j}}{d \phi}>0$.

Proof. The conditions of Proposition 5 imply that $\left.\frac{d s_{j}}{d \phi}\right|_{s_{k}}<0$. Propositions 2 and 3 then imply that $\frac{d s_{j}}{d \phi}<0$ and $\frac{d I_{j}}{d \phi}>0$. QED

Proposition 6 If $0.5>\pi-f>p, \frac{\partial^{2} p}{\partial s \partial \sigma}<0$, utility is CARA, and the conditions of Proposition 1 hold, then $\left.\frac{d s_{j}}{d \sigma}\right|_{s_{k}}>0$ and $\left.\frac{d I_{j}}{d \sigma}\right|_{s_{k}}<0$.

Proof. In the text, it was shown that these conditions imply $Q_{I_{j} \sigma}<0$ and $Q_{s_{j} \sigma}>0$. The proof of Proposition 4 showed that they implied $Q_{I_{j} s_{j}}<0$. Standard comparative statics arguments imply that:

$$
\begin{aligned}
& \left.\frac{d s_{j}}{d \sigma}\right|_{s_{k}}=\frac{-Q_{I_{j} I_{j}} Q_{s_{j} \sigma}+Q_{I_{j} \sigma} Q_{I_{j} s_{j}}}{D} \\
& \left.\frac{d I_{j}}{d \sigma}\right|_{s_{k}}=\frac{-Q_{I_{j} \sigma} Q_{s_{j} s_{j}}+Q_{s_{j} \sigma} Q_{s_{j} I_{j}}}{D}
\end{aligned}
$$

The results then follow from these expressions. QED

Corollary 6.1 Under the conditions of Propositions 1, 2, and 6, $\frac{d s_{j}}{d \sigma}>0$, and $\frac{d I_{j}}{d \sigma}<$ 0 .

Proof. Proposition 6 implies that $\left.\frac{d s_{j}}{d \sigma}\right|_{s_{k}}>0$. Corollary 3.1 then implies that $\frac{d s_{j}}{d \sigma}>0$, and $\frac{d I_{j}}{d \sigma}<0$. QED.

Proposition 7 If $0.5>\pi-f>p, \sigma$ and $s$ are perfect substitutes $\left(\frac{\partial p_{j}}{\partial s_{j}}=\frac{\partial p_{j}}{\partial \sigma}<\right.$ $\left.0, \frac{\partial^{2} p_{j}}{\partial s_{j} \partial \sigma}=\frac{\partial^{2} p_{j}}{\partial s_{j} \partial \sigma}>0\right)$, the conditions of Proposition 1 hold, and CARA utility, then $\left.\frac{d s_{j}}{d \sigma}\right|_{s_{k}}<0$ and $\left.\frac{d I_{j}}{d \sigma}\right|_{s_{k}}=0$.

Proof. These conditions imply that $Q_{I_{j} \sigma}=Q_{I_{j} s_{j}}$ and $Q_{s_{j} \sigma}=Q_{s_{j} s_{j}}$. Comparative statics (and substitution) yields:

$$
\begin{gathered}
\left.\frac{d s_{j}}{d \sigma}\right|_{s_{k}}=\frac{-Q_{I_{j} I_{j}} Q_{s_{j} s_{j}}+Q_{I_{j} s_{j}} Q_{I_{j} s_{j}}}{D}=\frac{-D}{D}<0 \\
\left.\frac{d I_{j}}{d \sigma}\right|_{s_{k}}=\frac{-Q_{I_{j} s_{j}} Q_{s_{j} s_{j}}+Q_{I_{j} s_{j}} Q_{s_{j} s_{j}}}{D}=0
\end{gathered}
$$

\section{QED.}

Corollary 7.1 Under the conditions of Propositions 1, 2, and $7, \frac{d s_{j}}{d \sigma}<0$, and $\frac{d I_{j}}{d \sigma}=$ 0 .

Proof. Proposition 7 implies that $\left.\frac{d s_{j}}{d \sigma}\right|_{s_{k}}<0$ and $\left.\frac{d I_{j}}{d \sigma}\right|_{s_{k}}=0$. Corollary 3.1 then implies that $\frac{d s_{j}}{d \sigma}>0$, and $\frac{d I_{j}}{d \sigma}<0$. QED. 


\section{References}

Ayres, I., and S. D. Levitt (1998). "Measuring Positive Externalities From Unobservable Victim Precaution: An Empirical Analysis of Lojack." Quarterly Journal of Economics 113(1):43-77.

Diamond, D. W., and P. H. Dybvig (1983). "Bank Runs, Deposit Insurance, and Liquidity." Journal of Political Economy 91(3):401-19.

Eck, J. E. (1993). "The Threat of Crime Displacement." Criminal Justice Abstracts 25(3):527-546.

Ehrlich, I., and G. S. Becker (1972). "Market Insurance, Self-Insurance, and SelfProtection." Journal of Political Economy 80(4):623-648.

Froot, K. A. (1997). "The Limited Financing of Catastrophe Risk: An Overview." Working Paper 6025. Cambridge, MA: National Bureau of Economic Research.

Hirshleifer, J. (1953). "War Damage Insurance." Review of Economics and Statistics 35(2):144-153.

Major, J. A. (2002). "Advanced Techniques for Modeling Terrorism Risk." Technical report. Guy Carpenter and Company, Inc.

McCool, T. J. (2001). "Terrorism Insurance: Alternative Programs for Protecting Insurance Consumers." Testimony Before the Senate Committee on Banking, Housing and Urban Affairs.

Peltzman, S. (1975). "The Effects of Automobile Safety Regulation." Journal of Political Economy 83(4):677-726.

Pigou, A. C. (1932). Economics of Welfare. London: Macmillan and Co., 4th edition. 